\title{
Evaluation of the Potential Pharmacokinetic Interactions Between Vixotrigine and an Oral Contraceptive
}

\author{
Yuan Zhao $^{1} \cdot$ Mark Versavel $^{2} \cdot$ Beth Tidemann-Miller $^{3} \cdot$ Romy Christmann $^{4} \cdot$ Himanshu Naik $^{1}$ (i)
}

Published online: 20 June 2020

(c) The Author(s) 2020

\begin{abstract} were collected for pharmacokinetic analysis. Safety was assessed. alone were deemed related to the study drug by the investigators. no clinically relevant effect on exposure of all three compounds.

\section{Introduction}

Trigeminal neuralgia (TN) is a rare, chronic neuropathic pain condition characterized by sudden and unilateral severe, brief, stabbing recurrent pain in one or more branches of the
\end{abstract}

Background and Objective Vixotrigine is a voltage- and use-dependent sodium channel blocker in development for neuropathic pain management. This study evaluated the effect of coadministration of vixotrigine (metabolized primarily via uridine diphosphate-glucuronosyltransferases) and an oral contraceptive containing ethinyl estradiol (uridine diphosphateglucuronosyltransferase inducer) and levonorgestrel on the pharmacokinetics and safety of all three compounds.

Methods In this phase I, open-label, fixed-sequence, multiple-dose study, 36 healthy women received oral vixotrigine $150 \mathrm{mg}$ three times daily for 6 days and once on day 7 . This was followed by a washout period, days $8-11$. The oral contraceptive was administered alone on days 12-25 and with vixotrigine $150 \mathrm{mg}$ three times daily on days 26-32. Serial blood samples

Results The geometric least-squares mean ratios (90\% confidence intervals) for the area under the concentration-time curve over $8 \mathrm{~h}$ and maximum concentration of vixotrigine co-administered with an oral contraceptive vs vixotrigine alone were $0.85(0.82-0.89)$ and $0.91(0.87-0.96)$, respectively. The geometric least-squares mean ratios (90\% confidence interval) for area under the concentration-time curve over $24 \mathrm{~h}$ and maximum concentration of ethinyl estradiol with vixotrigine vs ethinyl estradiol alone were $0.94(0.91-0.97)$ and $0.89(0.84-0.94)$, respectively; the ratios for levonorgestrel with vixotrigine vs levonorgestrel alone were $1.06(0.98-1.16)$ and $1.05(0.98-1.13)$, respectively. No adverse events occurring with vixotrigine

Conclusions Coadministration of vixotrigine and an oral contraceptive containing ethinyl estradiol and levonorgestrel had

Trial Registration ClinicalTrials.gov registration number: NCT03324685 (registered 25 October, 2017).

Previous Presentation of Data These results were previously presented at the American Society for Clinical Pharmacology and Therapeutics (ASCPT) 120th Annual Meeting, 13-16 March, 2019, Washington, DC, USA.

\section{Himanshu Naik}

himanshu.naik@biogen.com

1 Clinical Pharmacology and Pharmacometrics, Biogen, 225 Binney Street, Cambridge, MA 02142, USA

2 vZenium, Arlington, MA, USA

3 Biostatistics, Biogen, Cambridge, MA, USA

4 Global Safety Regulatory Sciences, Biogen, Cambridge, MA, USA fifth cranial nerve [1]. The incidence of TN has a range from 8.0 to 28.9 per 100,000 person-years and prevalence is estimated to be between $0.03 \%$ and $0.3 \%[2,3]$. The pain of TN can be severe in intensity and triggered by ordinary activities including talking, chewing, eating, and the brushing of teeth [4]. Although patients with TN experience periods of remission, up to half have continuous or nearly continuous pain between attacks [4, 5]. Treatment options for TN are limited; carbamazepine, a sodium channel blocker, is recommended as a first-line treatment for pain control in patients with $\mathrm{TN}$ $[6,7]$, but has a problematic safety and tolerability profile that includes tiredness, sleepiness, concentration difficulties, dizziness, liver damage, and cognitive impairment [7-12]. Patients may require invasive surgical options. Moreover, with a longer duration, TN may become more severe and increasingly intractable to treatment [7], indicating a need for drugs with better efficacy and safety profiles.

Vixotrigine (formerly GSK1014802, CNV1014802, raxatrigine, BIIB074) is a voltage- and use-dependent 


\section{Key Points}

Vixotrigine, in development for neuropathic pain management, is primarily metabolized via uridine diphosphate-glucuronosyltransferases (UGTs). Many oral contraceptives contain ethinyl estradiol (a UGT inducer). The effect of coadministration of vixotrigine and ethinyl estradiol-based oral contraceptives on the pharmacokinetics and safety of vixotrigine and the oral contraceptive's components is unknown.

This study's findings demonstrate that coadministration of vixotrigine and an oral contraceptive containing ethinyl estradiol has no clinically relevant effects on the exposure or safety of vixotrigine or an oral contraceptive's components.

Women who use an ethinyl estradiol-based oral contraceptive can participate in clinical trials of vixotrigine or receive vixotrigine as treatment without changing their contraception method. sodium (Nav) channel blocker that is in development for the treatment of $\mathrm{TN}$ and other neuropathic pain conditions (NCT03339336, NCT04106050, NCT03070132, NCT03637387) [13, 14]. Preclinical data have shown that vixotrigine has higher potency and more profound state- and use-dependent inhibition than carbamazepine across Nav channels (data on file, Biogen). The pharmacokinetics of vixotrigine has been well characterized [14-21]. Previous studies have showed that vixotrigine is rapidly absorbed, with maximum plasma concentrations attained approximately $2 \mathrm{~h}$ post-dose, and has moderate-to-extensive tissue distribution $[17,18,20]$. The elimination half-life of vixotrigine at single doses of 75-825 mg has been found to be approximately $11 \mathrm{~h}$ [18]. In general, the maximum concentration $\left(C_{\max }\right)$ and area under the concentration-time curve (AUC) from time zero to infinity increased in an approximately dose-proportional manner after a single dose (10-825 mg) and multiple doses $(150-400 \mathrm{mg})[17,18]$. Vixotrigine is metabolized primarily via uridine diphosphate-glucuronosyltransferases (UGTs), and cytochrome P450 enzymes play only a minor role in its metabolism $[16,19]$. The major metabolite of vixotrigine is M13, which is formed by $N$-carbamoyl glucuronidation of the pyrrolidine ring and represents, on a molar basis, $40 \%$ of the administered vixotrigine dose excreted in urine [16]. Minor metabolites include M14 (formed by amide hydrolysis) and M16 (formed by oxidation of M14), which comprise $24 \%$ and $<1 \%$, respectively, of the dose excreted in urine [16].
Oral contraceptives are among the most common forms of contraception; approximately $13 \%$ and $27-30 \%$ of women aged 15-49 years in the USA and Europe, respectively, choose this method for pregnancy prevention [22-24]. Oral contraceptives may also be prescribed for non-contraceptive purposes including control of menstrual irregularities, treatment of dysmenorrhea, premenstrual syndrome, acne, and prevention of endometrial, ovarian, and colorectal cancer [25]. Vixotrigine has the potential to be administered to women receiving concomitant oral contraceptives containing ethinyl estradiol in phase III trials or in the clinical setting, particularly in light of the higher prevalence of TN (at least twofold) in women compared with men and the fact that approximately one-third of women with $\mathrm{TN}$ are $15-44$ years of age $[26,27]$. Because ethinyl estradiol is a known UGT inducer [28, 29], it is important to evaluate the potential for drug-drug interactions of vixotrigine and oral contraceptives containing ethinyl estradiol. A phase I study (NCT03324685) was conducted in healthy female volunteers to evaluate the effect of coadministration of vixotrigine and an oral contraceptive (ethinyl estradiol and levonorgestrel) on the pharmacokinetics and overall safety of the three compounds.

\section{Methods}

\subsection{Participants}

This study enrolled healthy female volunteers aged $18-45$ years who had a body mass index of $18-32 \mathrm{~kg} / \mathrm{m}^{2}$. Participants who were of childbearing potential were required to practice effective non-hormonal contraception during the study and for 5 weeks after their last dose of the study drug. None of the participants could have received any immunizations within 30 days before or during the study. Treatment with an oral, injected, or hormonal contraceptive or hormonal replacement therapy within 30 days of the start of the study was prohibited, as was the use of prescription or over-the-counter oral drugs (except acetaminophen), herbal supplements (e.g., St. John's wort), inducers or inhibitors of UGT or cytochrome P450 enzymes, and monoamine oxidase inhibitors within 14 days before the start of the study.

\subsection{Study Design}

This was a phase I, open-label, fixed-sequence, multipledose, single-site study (Covance Clinical Research Unit, Inc., Daytona Beach, FL, USA). Participants were administered oral vixotrigine $150 \mathrm{mg}$ (supplied by study sponsor as 150 -mg tablets and stored at $\leq 30{ }^{\circ} \mathrm{C}$ ) three times daily on days 1-6 and a single 150-mg dose on the morning of day 7 , which was followed by a 5 -day washout period (days 
$8-11)$. On day 12 , participants received a single dose of the oral contraceptive (ethinyl estradiol $30 \mu \mathrm{g}$ and levonorgestrel $150 \mu \mathrm{g}$, which are standard doses for contraceptive purposes [30]; Portia, Pandia Health, Sunnyvale, CA, USA; inactive tablets removed) and then self-administered the oral contraceptive (at the same dose as on day 12) once daily at approximately the same time on days 13 through 23. Participants then returned to the clinic and received a single morning dose of an oral contraceptive on days 24 and 25 . Vixotrigine $150 \mathrm{mg}$ three times daily was co-administered with an oral contraceptive on days 26-32 (Fig. 1). Morning doses of study drugs were administered following 8-h fasts on days 7,25 , and 32 . The selected dosing regimens for vixotrigine ( 7 days) and an oral contraceptive (21 days, including 13 days before pharmacokinetic evaluation) were sufficient to achieve steady state at 7 days and 12-13 days, respectively, based on the half-lives of vixotrigine $(\sim 11 \mathrm{~h})$, ethinyl estradiol (18 h), and levonorgestrel (36 h) [18, 31], and to evaluate the effects of each agent on the other at the $C_{\max }$ that could be observed in the clinic.

\subsection{Assessments}

Blood samples were collected for pharmacokinetic analysis of vixotrigine and its metabolites (M13, M14, and M16) on days 7 and 32 (morning dose) at $0.5 \mathrm{~h}$ pre-dose and $0.5,1$, $2,3,4,6$, and $8 \mathrm{~h}$ post-dose. For each sample, $4 \mathrm{~mL}$ of blood was collected into a $\mathrm{K}_{2}$ EDTA tube, gently mixed, and kept on ice. Within $1 \mathrm{~h}$ of collection, samples were centrifuged at $4{ }^{\circ} \mathrm{C}$ for $10 \mathrm{~min}$ at $1500 \mathrm{G}$. Plasma was aliquoted equally into two $2-\mathrm{mL}$ cryovials and stored at $-70{ }^{\circ} \mathrm{C}$. The final sample on day 32 occurred before the second dose. For pharmacokinetic analysis of ethinyl estradiol and levonorgestrel, blood was collected on days 25 and 32 at $0.5 \mathrm{~h}$ before dosing and $0.5,1,2,3,4,6,8,12,16$, and 24 h post-dose and on days 12 and 24 pre-dose. A pre-dose blood sample was collected on day 12 to confirm washout from any previous oral contraceptive use. Determination of plasma concentrations of all compounds was performed at Covance Bioanalytical Services, LLC, Indianapolis, IN, USA. The analytical matrix used for all analyses was $\mathrm{K}_{2}$ EDTA plasma. Plasma concentrations of vixotrigine and its M13, M14, and M16 metabolites were determined using liquid chromatography-tandem mass spectrometry after protein precipitation extraction according to validated analytical methods as described previously [14]. The lower limit of quantification (LLOQ) for vixotrigine and M13, M14, and M16 metabolites was $10 \mathrm{ng} / \mathrm{mL}$. Plasma concentrations of ethinyl estradiol were determined using liquid-liquid extraction followed by derivatization/liquid chromatography-tandem mass spectrometry. The validated range was from 0.0075 to $0.500 \mathrm{ng} / \mathrm{mL}$, and quality control levels were $0.0075 \mathrm{ng} / \mathrm{mL}$ (LLOQ), $0.018 \mathrm{ng} / \mathrm{mL}$, $0.0600 \mathrm{pg} / \mathrm{mL}, 0.380 \mathrm{ng} / \mathrm{mL}$, and $2.500 \mathrm{ng} / \mathrm{mL}$. The ranges for relative standard deviation (\%RSD) and percent bias (\% bias) for intra-assay precision and accuracy, respectively, were $0.7-6.5 \%$ and -7.9 to $-1.0 \%$. The ranges for inter-assay \%RSD and \%bias, respectively, were $2.1-5.5 \%$ and -5.9 to $-4.5 \%$. Plasma concentrations of levonorgestrel were determined with supported-liquid extraction/ liquid chromatography-tandem mass spectrometry. The validated range was $0.150-10.0 \mathrm{ng} / \mathrm{mL}$, and quality control levels were $0.150 \mathrm{ng} / \mathrm{mL}$ (LLOQ), $0.450 \mathrm{ng} / \mathrm{mL}, 4.50 \mathrm{ng} / \mathrm{mL}$,

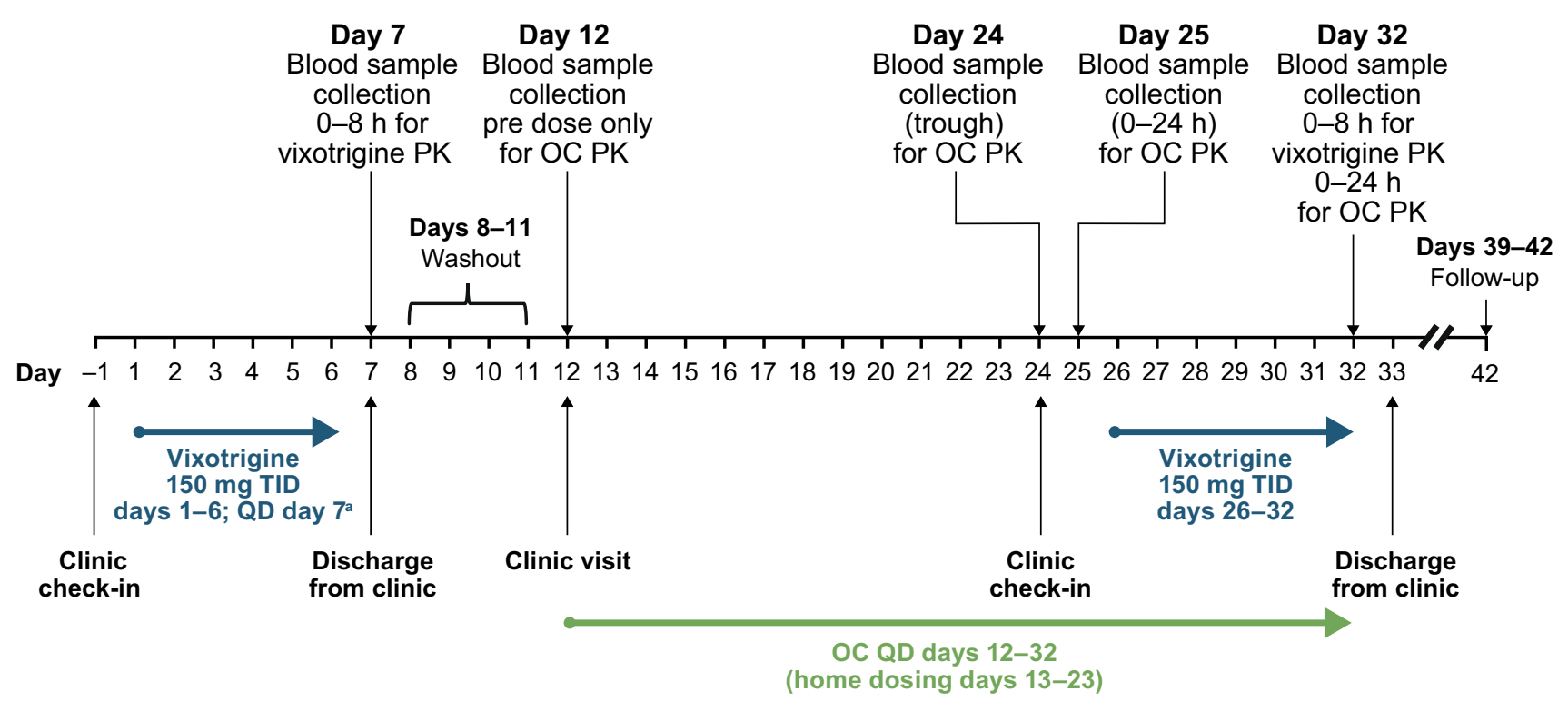

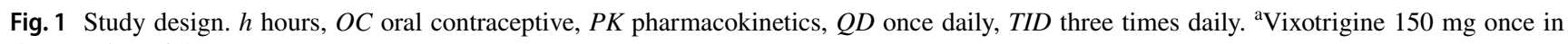
the morning of day 7 
$7.50 \mathrm{ng} / \mathrm{mL}$, and $50.0 \mathrm{ng} / \mathrm{mL}$. The ranges for intra-assay $\%$ RSD and \%bias, respectively, were $2.7-11.9 \%$ and -4.6 to $12.4 \%$. The ranges for inter-assay $\% \mathrm{RSD}$ and $\%$ bias, respectively, were $6.5-11.2 \%$ and $1.3-5.8 \%$.

Blood was also collected for clinical laboratory evaluations. Safety was assessed throughout the study via the monitoring of adverse events (AEs), clinical laboratory evaluations (blood and urine collected pre-dose on days 3, 7, 24 , and 28), vital sign measurements, 12-lead electrocardiograms, and physical examinations. All AEs were described using MedDRA (Version 20.0).

The primary endpoints included $C_{\max }$ and AUC from time 0 to $8 \mathrm{~h}$ post-dose $\left(\mathrm{AUC}_{8}\right)$ for vixotrigine on days 7 and 32, and $C_{\max }$ and AUC from time zero to $24 \mathrm{~h}$ post-dose $\left(\mathrm{AUC}_{24}\right)$ for ethinyl estradiol and levonorgestrel on days 25 and 32 . Secondary and other endpoints included $\mathrm{AUC}_{8}$ and $C_{\max }$ of vixotrigine metabolites M13, M14, and M16 on days 7 and 32, time to reach $C_{\max }\left(T_{\max }\right)$, half-life, apparent total plasma clearance at steady state, and apparent volume of distribution at steady state for vixotrigine on days 7 and 32 and for ethinyl estradiol and levonorgestrel on days 25 and 32 .

\subsection{Pharmacokinetic Analysis}

Pharmacokinetic analysis was performed using noncompartmental methods from Phoenix WinNonlin (Certara, USA, Inc., Princeton, NJ, USA; Version 6.4). $\mathrm{AUC}_{8}$ of vixotrigine and its metabolites and $\mathrm{AUC}_{24}$ of ethinyl estradiol and levonorgestrel were calculated using the linear trapezoidal rule for increasing concentrations and the logarithmic rule for decreasing concentrations. Plasma concentrations for vixotrigine and its metabolites and for ethinyl estradiol and levonorgestrel were summarized with descriptive statistics. Mixed-effects models (treatment period as fixed effect and participant as random effect) were used to analyze the effect of the oral contraceptive on the natural $\log$-transformed $\mathrm{AUC}_{8}$ and $C_{\max }$ of vixotrigine and its metabolites and the effect of vixotrigine on the natural log-transformed $\mathrm{AUC}_{24}$ and $C_{\max }$ of the oral contraceptive. The least-squares (LS) mean differences for each model (vixotrigine plus an oral contraceptive vs vixotrigine alone; vixotrigine plus oral contraceptive vs an oral contraceptive alone) and the corresponding 90\% confidence intervals (CIs) were obtained and exponentiated to provide the geometric LS mean ratios (vixotrigine plus an oral contraceptive/ vixotrigine alone; vixotrigine plus an oral contraceptive/ oral contraceptive alone) and corresponding $90 \%$ CIs. A lack of drug interaction between vixotrigine and an oral contraceptive is demonstrated if the $90 \%$ CIs fall within the interval $[0.80,1.25]$.

Participants were included in the pharmacokinetic analysis if they had one or more measurable post-dose concentrations of vixotrigine, ethinyl estradiol, or levonorgestrel and did not have any major protocol deviations. For a participant's data to be included in calculations of AUC, three or more measures of the analyte had to exceed the LLOQ with one or more measure occurring after $C_{\max }$. All participants who had received one or more doses of the treatment drug were assessed for safety. All statistical analyses were performed using SAS version 9.2 (SAS Institute, Cary, NC, USA).

Assuming a true mean ratio of 0.95 and an intra-subject coefficient of variation of up to $22 \%$, a sample size of 29 evaluable participants would provide $\geq 90 \%$ power that the $90 \%$ CIs of the geometric mean ratios for the $C_{\max }$ and AUC endpoint comparisons would be within the interval of $0.80-1.25$ [32]. To account for potential dropouts or for volunteers lacking sufficient data for analysis, 36 participants were enrolled.

\section{Results}

\subsection{Participant Disposition and Demographics}

In total, 36 female participants were enrolled and 33 completed the study. Reasons for discontinuation included AEs (dysmenorrhea, $n=1$; increased alanine aminotransferase, $n=1)$ and participant decision $(n=1)$. The mean (standard deviation) age of participants was 31.5 (9.8) years and mean (standard deviation) body mass index was $25.5(3.3) \mathrm{kg} / \mathrm{m}^{2}$ (Table 1). Slightly more than half $(55.6 \%)$ of participants were white.

\subsection{Pharmacokinetics}

Of 36 enrolled participants, 35 were available for pharmacokinetic analysis and one was excluded owing to major protocol deviations (three missed or late oral contraceptive doses). Vixotrigine was rapidly absorbed when administered alone (median $T_{\max }=1.5 \mathrm{~h}$ ) or with the oral contraceptive (median $T_{\max }=1.0 \mathrm{~h}$; Table 2). Following repeated daily dosing of an oral contraceptive, arithmetic mean

Table 1 Participant demographics $(N=36)$

\begin{tabular}{lc}
\hline Parameter & Value \\
\hline Age (years) & $31.5(9.8)$ \\
Height $(\mathrm{cm})$ & $161.4(7.0)$ \\
Weight $(\mathrm{kg})$ & $66.6(11.1)$ \\
Body mass index $\left(\mathrm{kg} / \mathrm{m}^{2}\right)$ & $25.5(3.3)$ \\
Race $[n(\%)]$ & \\
White & $20(55.6)$ \\
Black & $15(41.7)$ \\
Asian & $1(2.8)$ \\
\hline
\end{tabular}

Data are mean (standard deviation) unless stated otherwise 
plasma concentrations of vixotrigine were slightly reduced compared with when vixotrigine was administered alone (Table 2, Fig. 2a). The geometric LS mean ratios (90\% CI) for $\mathrm{AUC}_{8}$ and $C_{\text {max }}$, respectively, of vixotrigine when coadministered with an oral contraceptive vs vixotrigine alone were 0.85 (0.82-0.89) and 0.91 (0.87-0.96; Table 3).

Oral contraceptive dosing had negligible effects on the mean arithmetic plasma concentration of vixotrigine metabolite M13 (Fig. 2b). The geometric LS mean ratios (90\% CI) for $\mathrm{AUC}_{8}$ and $C_{\max }$, respectively, of M13 when vixotrigine was administered alone vs with an oral contraceptive were 1.00 (0.97-1.04) and 1.03 (0.98-1.09; Table 3). In contrast, coadministration of vixotrigine and an oral contraceptive substantially decreased the arithmetic mean plasma concentrations of vixotrigine metabolites M14 and M16 (Fig. 2c, d). The geometric LS mean ratios $(90 \% \mathrm{CI})$ for the $\mathrm{AUC}_{8}$ and $C_{\max }$ of metabolite M14 were $0.76(0.72-0.80)$ and 0.80
(0.75-0.85), respectively, indicating a reduction in exposure of $\sim 20-24 \%$ (Table 3). Similarly, for M16, the geometric LS mean ratios $(90 \% \mathrm{CI})$ for $\mathrm{AUC}_{8}$ and $C_{\max }$ were 0.60 (0.56-0.65) and $0.62(0.58-0.67)$, respectively (Table 3$)$, indicating a reduction in exposure of $\sim 38-40 \%$.

Absorption of ethinyl estradiol and levonorgestrel occurred rapidly following treatment with the oral contraceptive alone (median $T_{\max }=1.0 \mathrm{~h}$ for both) and in combination with vixotrigine (median $T_{\max }=2.0 \mathrm{~h}$ and $1.0 \mathrm{~h}$, respectively; Table 2). The arithmetic mean plasma concentrations of ethinyl estradiol and levonorgestrel were similar when administered alone and with vixotrigine (Table 2; Fig. 3). The geometric LS mean ratios $(90 \% \mathrm{CI})$ for $\mathrm{AUC}_{24}$ and $C_{\max }$, respectively, of ethinyl estradiol when co-administered with vixotrigine vs alone were 0.94 (0.91-0.97) and 0.89 (0.84-0.94), and of levonorgestrel with vixotrigine vs levonorgestrel alone were $1.06(0.98-1.16)$ and 1.05

Table 2 Summary of vixotrigine and oral contraceptive plasma pharmacokinetic parameters when administered alone and co-administered

\begin{tabular}{|c|c|c|c|c|}
\hline Parameter & $n$ & Vixotrigine alone $(n=35)$ & $n$ & $\begin{array}{l}\text { Vixotrigine }+ \text { oral } \\
\text { contraceptive } \\
(n=32)\end{array}$ \\
\hline \multicolumn{5}{|l|}{ Vixotrigine } \\
\hline $\mathrm{AUC}_{8}(\mathrm{~h} \bullet \mathrm{ng} / \mathrm{mL})$ & 34 & $20,752.2(4244.4)$ & 32 & $17,658.8(3099.9)$ \\
\hline$C_{\max }(\mathrm{ng} / \mathrm{mL})$ & 34 & $3462.1(697.0)$ & 32 & $3149.7(545.9)$ \\
\hline$T_{\max }(\mathrm{h})$, median (range) & 34 & $1.5(1.0-3.0)$ & 32 & $1.0(1.0-4.0)$ \\
\hline$t_{1 / 2}(\mathrm{~h})$ & 29 & $9.5(3.7)$ & 29 & $8.5(6.7)$ \\
\hline $\mathrm{CL}_{\mathrm{ss}} / \mathrm{F}(\mathrm{L} / \mathrm{h})$ & 34 & $7.5(1.6)$ & 32 & $8.8(1.6)$ \\
\hline \multirow[t]{2}{*}{$V_{\mathrm{ss}} / \mathrm{F}(\mathrm{L})$} & 29 & $102.6(38.2)$ & 29 & $105.1(76.9)$ \\
\hline & \multicolumn{3}{|c|}{ Oral contraceptive alone $(n=35)$} & $\begin{array}{l}\text { Vixotrigine }+ \text { oral } \\
\text { contraceptive } \\
(n=32)\end{array}$ \\
\hline \multicolumn{5}{|l|}{ Ethinyl estradiol } \\
\hline $\mathrm{AUC}_{24}(\mathrm{~h} \bullet \mathrm{ng} / \mathrm{mL})$ & 35 & $0.933(0.279)$ & 32 & $0.875(0.261)$ \\
\hline$C_{\max }(\mathrm{ng} / \mathrm{mL})$ & 35 & $0.104(0.035)$ & 32 & $0.092(0.032)$ \\
\hline$T_{\max }(\mathrm{h})$, median (range) & 35 & $1.0(1.0-3.0)$ & 32 & $2.0(1.0-4.0)$ \\
\hline$t_{1 / 2}(\mathrm{~h})$ & 35 & $12.6(3.6)$ & 32 & $15.6(4.6)$ \\
\hline $\mathrm{CL}_{\mathrm{ss}} / \mathrm{F}(\mathrm{L} / \mathrm{h})$ & 35 & $34.8(9.6)$ & 32 & $37.3(11.1)$ \\
\hline$V_{\mathrm{ss}} / \mathrm{F}(\mathrm{L})$ & 35 & $610.4(177.5)$ & 32 & $823.5(301.5)$ \\
\hline \multicolumn{5}{|l|}{ Levonorgestrel } \\
\hline $\mathrm{AUC}_{24}(\mathrm{~h} \bullet \mathrm{ng} / \mathrm{mL})$ & 35 & 80.9 (43.9) & 32 & $78.5(34.5)$ \\
\hline$C_{\max }(\mathrm{ng} / \mathrm{mL})$ & 35 & $7.0(3.3)$ & 32 & $7.0(2.7)$ \\
\hline$T_{\max }(\mathrm{h})$, median (range) & 35 & $1.00(0.5-3.0)$ & 32 & $1.00(0.5-3.0)$ \\
\hline$t_{1 / 2}(\mathrm{~h})$ & 34 & $34.4(16.7)$ & 31 & $33.1(12.3)$ \\
\hline $\mathrm{CL}_{\mathrm{ss}} / \mathrm{F}(\mathrm{L} / \mathrm{h})$ & 35 & $2.7(2.1)$ & 32 & $2.3(1.1)$ \\
\hline$V_{\mathrm{ss}} / \mathrm{F}(\mathrm{L})$ & 34 & $119.2(94.6)$ & 31 & $110.3(65.5)$ \\
\hline
\end{tabular}

Data are mean (standard deviation) unless stated otherwise. The sample collection period may not have fully captured the terminal phase. For nearly all participants, the reported $t_{1 / 2}$ values were determined over a period of more than twice the resulting $t_{1 / 2}$ and should be interpreted cautiously

$A U C_{8}$ area under the concentration-time curve from time zero to 8 hours post-dose, $A U C_{24}$ area under the concentration-time curve from time zero to 24 hours post-dose, $C L_{s s} / F$ apparent clearance at steady state, $C_{\max }$ maximum concentration, $h$ hours, $t_{1 / 2}$ half-life, $T_{\max }$ time to $C_{\max }$, $V_{s s} / F$ apparent volume of distribution at steady state 

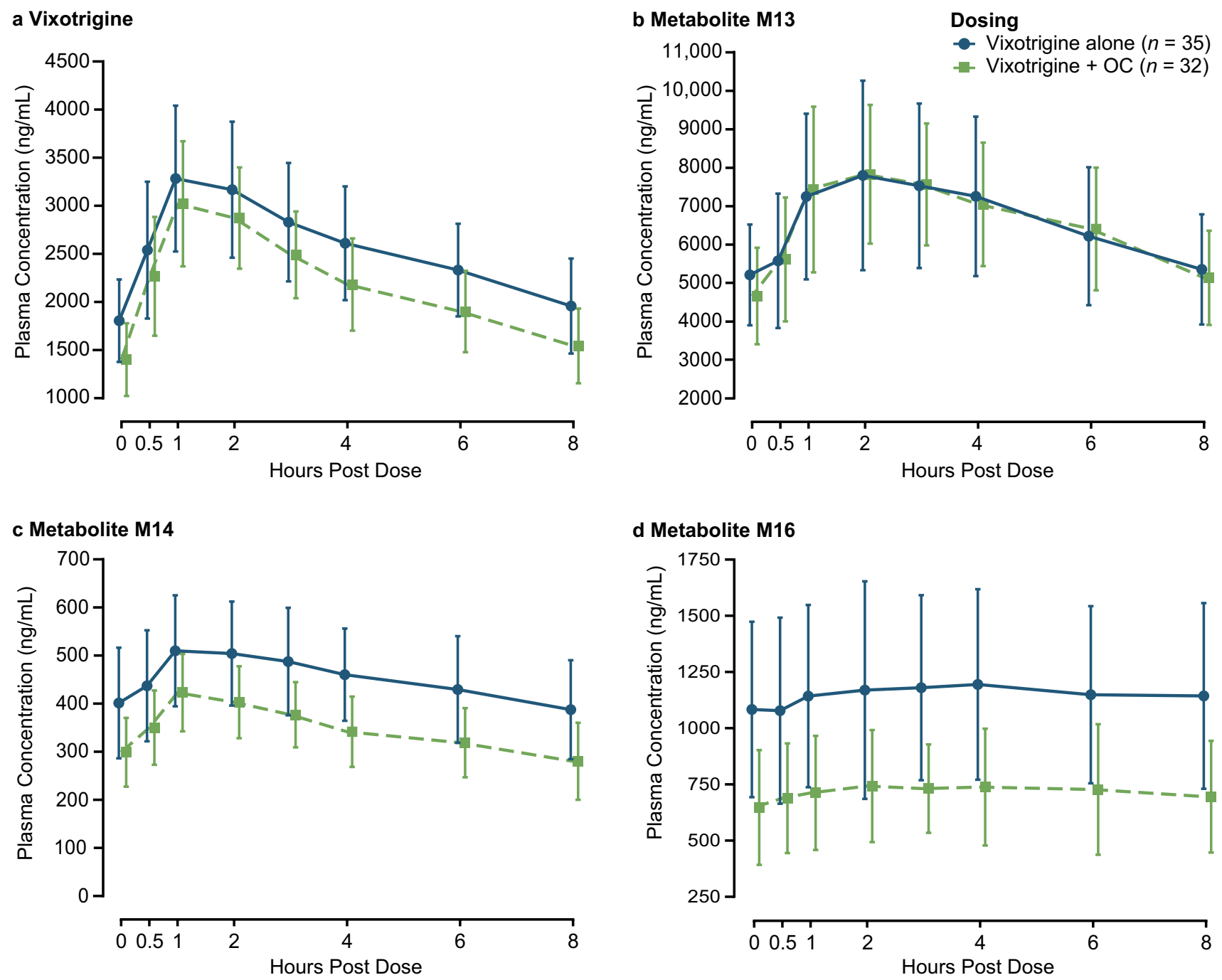

Fig. 2 Arithmetic mean ( \pm standard deviation) plasma concentration profiles of a vixotrigine, b metabolite M13, c metabolite M14, and d metabolite M16 when vixotrigine was administered alone and with coadministration of an oral contraceptive (OC)

(0.98-1.13; Table 3), indicating that vixotrigine had a negligible effect on the plasma exposure of either oral contraceptive component. Additional pharmacokinetic findings for vixotrigine, ethinyl estradiol, and levonorgestrel are shown in Table 2.

\subsection{Safety}

A total of 17 of 36 participants (47.2\%) reported 24 treatment-emergent AEs (TEAEs) during the study period (Table 4). Six participants (16.7\%) reported nine TEAEs from administration of vixotrigine alone, five participants (13.9\%) reported five TEAEs from administration of the oral contraceptive alone, and six participants (16.7\%) reported nine TEAEs from coadministration of vixotrigine and the oral contraceptive. The most common TEAEs reported (in more than one participant) included upper respiratory tract infection $(n=3)$, headache $(n=3)$, increased alanine aminotransferase $(n=3)$, and cough $(n=2)$. Other TEAEs were reported by single participants only. The TEAEs reported after the administration of vixotrigine alone were not deemed related to treatment by the investigator. Treatmentemergent AEs reported during coadministration of vixotrigine and the oral contraceptive that were considered related to the study drug (either vixotrigine plus an oral contraceptive or an oral contraceptive alone) included increased alanine aminotransferase ( $n=2$; one participant had an increase of approximately two times the upper limit of normal and one had an increase of approximately three times the upper limit of normal, which led to study withdrawal; Hy's law was not met at any point during the study), oral herpes $(n=1)$, and headache $(n=1)$. One participant had acute cholecystitis at 
Table 3 Statistical analysis of the exposure of coadministration of vixotrigine and oral contraceptive

\begin{tabular}{|c|c|c|c|c|}
\hline \multirow[t]{2}{*}{ Analyte } & \multirow[t]{2}{*}{ Parameter } & \multicolumn{2}{|l|}{ Geometric LS mean } & \multirow[t]{2}{*}{ Ratio $(90 \% \mathrm{CI})^{\mathrm{a}}$} \\
\hline & & Vixotrigine alone $(n=35)$ & $\begin{array}{l}\text { Vixotrigine }+ \text { oral contraceptive } \\
(n=32)\end{array}$ & \\
\hline \multirow[t]{2}{*}{ Vixotrigine } & $\mathrm{AUC}_{8}(\mathrm{~h} \bullet \mathrm{ng} / \mathrm{mL})$ & $20,257.03^{b}$ & $17,271.00$ & $0.85(0.82-0.89)$ \\
\hline & $C_{\max }(\mathrm{ng} / \mathrm{mL})$ & $3385.83^{\mathrm{b}}$ & 3083.55 & $0.91(0.87-0.96)$ \\
\hline \multirow[t]{2}{*}{ Metabolite M13 } & $\mathrm{AUC}_{8}(\mathrm{~h} \bullet \mathrm{ng} / \mathrm{mL})$ & $51,338.99^{\mathrm{b}}$ & $51,404.56$ & $1.00(0.97-1.04)$ \\
\hline & $C_{\max }(\mathrm{ng} / \mathrm{mL})$ & $8045.27^{\mathrm{b}}$ & 8291.39 & $1.03(0.98-1.09)$ \\
\hline \multirow[t]{2}{*}{ Metabolite M14 } & $\mathrm{AUC}_{8}(\mathrm{~h} \bullet \mathrm{ng} / \mathrm{mL})$ & 3539.47 & $2686.76^{\mathrm{c}}$ & $0.76(0.72-0.80)$ \\
\hline & $C_{\max }(\mathrm{ng} / \mathrm{mL})$ & 536.68 & 428.61 & $0.80(0.75-0.85)$ \\
\hline \multirow[t]{3}{*}{ Metabolite M16 } & $\mathrm{AUC}_{8}(\mathrm{~h} \bullet \mathrm{ng} / \mathrm{mL})$ & $8872.68^{c}$ & 5363.07 & $0.60(0.56-0.65)$ \\
\hline & $C_{\max }(\mathrm{ng} / \mathrm{mL})$ & 1251.42 & $781.74^{\mathrm{d}}$ & $0.62(0.58-0.67)$ \\
\hline & & $\begin{array}{l}\text { Oral contraceptive alone } \\
(n=35)\end{array}$ & $\begin{array}{l}\text { Vixotrigine }+ \text { oral contraceptive } \\
(n=32)\end{array}$ & Ratio $(90 \% \mathrm{CI})^{\mathrm{e}}$ \\
\hline \multirow[t]{2}{*}{ Ethinyl estradiol } & $\mathrm{AUC}_{24}(\mathrm{~h} \bullet \mathrm{ng} / \mathrm{mL})$ & 0.90 & 0.84 & $0.94(0.91-0.97)$ \\
\hline & $C_{\max }(\mathrm{ng} / \mathrm{mL})$ & 0.10 & 0.09 & $0.89(0.84-0.94)$ \\
\hline \multirow[t]{2}{*}{ Levonorgestrel } & $\mathrm{AUC}_{24}(\mathrm{~h} \bullet \mathrm{ng} / \mathrm{mL})$ & 69.11 & 73.57 & $1.06(0.98-1.16)$ \\
\hline & $C_{\max }(\mathrm{ng} / \mathrm{mL})$ & 6.26 & 6.57 & $1.05(0.98-1.13)$ \\
\hline
\end{tabular}

$A U C_{8}$ area under the concentration-time curve from time zero to 8 hours post-dose, $A U C_{24}$ area under the concentration-time curve from time zero to 24 hours post-dose, $C I$ confidence interval, $C_{\max }$ maximum concentration, $L S$ least squares

${ }^{a}$ Ratio of geometric LS means of vixotrigine and oral contraceptive to vixotrigine alone

$\mathrm{b}_{n}=34$

${ }^{\mathrm{c}} n=31$

$\mathrm{d}_{n}=29$

${ }^{\mathrm{e}}$ Ratio of geometric LS means of vixotrigine and oral contraceptive to oral contraceptive alone

follow-up after study withdrawal, which was due to mild dysmenorrhea. The AE of acute cholecystitis was severe and considered serious and related to vixotrigine and the oral contraceptive by the investigator. This participant had a medical history of cholelithiasis, although the start date of this condition was unknown. The participant underwent laparoscopic cholecystectomy and the AE resolved after 3 days. No clinically significant findings in hematology, urinalysis, vital signs, electrocardiograms, or physical examinations were reported during the study.

\section{Discussion}

Vixotrigine is predominately metabolized to its primary metabolite M13 via glucuronidation mediated by the UGT isozymes UGT1A3 and UGT2B7 [14]. The potential pool of patients utilizing vixotrigine either in trials or the clinical setting will likely include women who use oral contraceptives containing ethinyl estradiol, a known UGT inducer [29], on the basis of drug interaction studies with propranolol and lamotrigine [33-35]. Therefore, this study was conducted to evaluate the effect of oral contraceptives on vixotrigine pharmacokinetics and the effect of vixotrigine on the pharmacokinetics of the components in the oral contraceptive.

The findings of this study show that coadministration of vixotrigine and an oral contraceptive containing ethinyl estradiol and levonorgestrel had no clinically relevant effect on the systemic exposure of vixotrigine, the UGT-mediated metabolite M13, or the oral contraceptive. In contrast, systemic exposure of vixotrigine metabolites M14 and M16 was reduced by coadministration of vixotrigine with the oral contraceptive; the $90 \%$ CIs for the geometric LS mean ratios for AUC and $C_{\max }$ of both metabolites fell outside the $0.80-1.25$ equivalence range. Because steady state was reached for both vixotrigine and the oral contraceptive, these findings are relevant in real-world settings where women will likely be taking both drugs for extended periods of time.

Although the systemic exposure of minor metabolites M14 and M16 was reduced by 20-24\% and 38-40\%, respectively, these findings were not considered clinically important because M14 and M16 show no activity against sodium channels Nav1.2, Nav1.6, Nav1.5, and Nav1.7 [14]. Both metabolites result from amide hydrolysis that is independent of the UGT metabolism pathway; their lower plasma exposures may reflect the decreased plasma concentrations of vixotrigine available for metabolism because the latter's 


\section{a Ethinyl Estradiol}

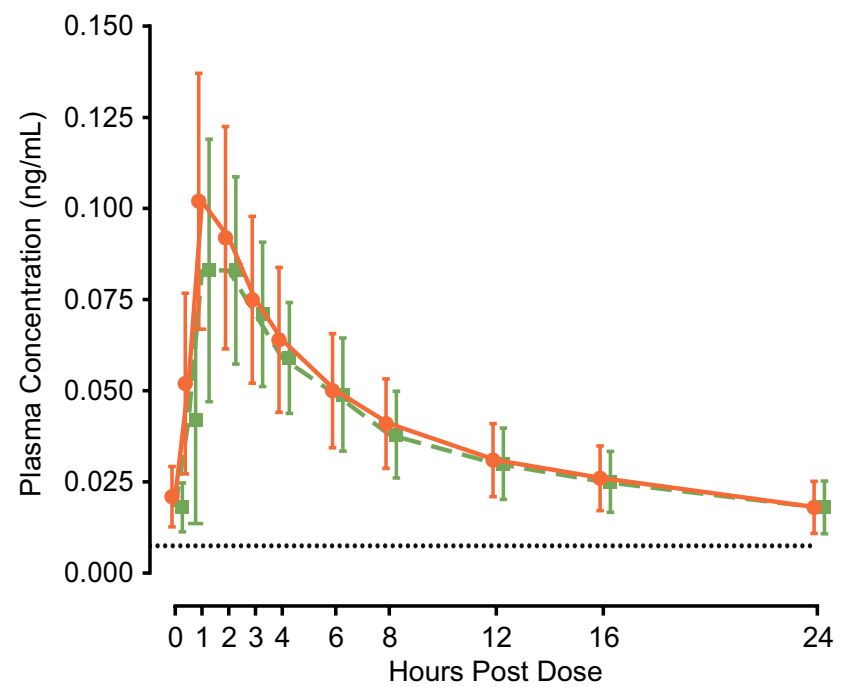

Fig. 3 Arithmetic mean ( \pm standard deviation) plasma concentration profiles of a ethinyl estradiol and $\mathbf{b}$ levonorgestrel when the combination of ethinyl estradiol and levonorgestrel was administered alone and with coadministration of vixotrigine. $O C$ oral contraceptive. Dot-

\section{b Levonorgestrel}

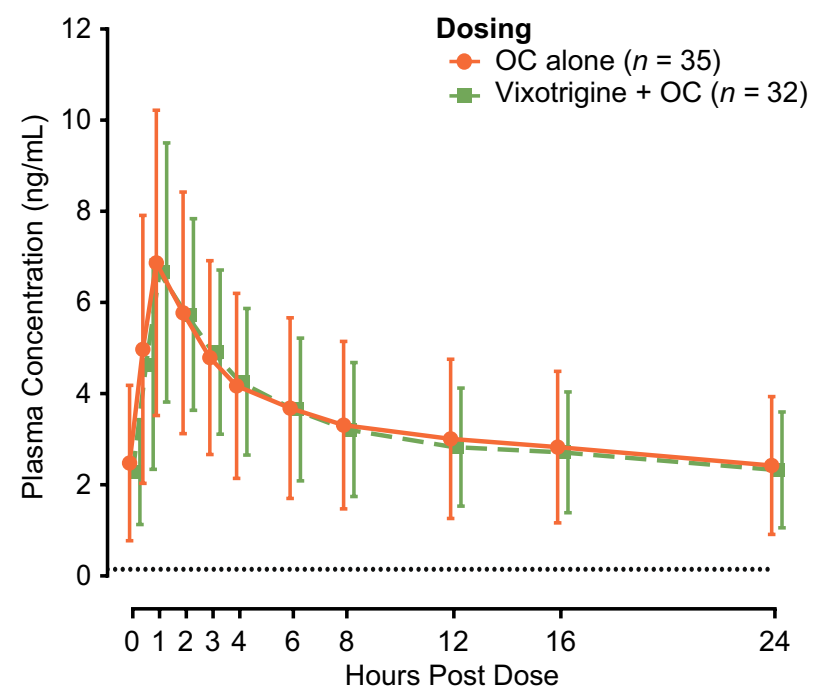

ted black lines in (a) and (b) indicate the lower limit of quantification for ethinyl estradiol $(0.0075 \mathrm{ng} / \mathrm{mL})$ and levonorgestrel $(0.15 \mathrm{ng} / \mathrm{mL})$, respectively

Table 4 Most common treatment-emergent adverse events (TEAEs) ${ }^{\mathrm{a}}$

\begin{tabular}{llllc}
\hline TEAE & $\begin{array}{l}\text { Vixotrigine alone } \\
(n=36)\end{array}$ & $\begin{array}{l}\text { Oral contraceptive alone } \\
(n=36)\end{array}$ & $\begin{array}{l}\text { Vixotrigine }+ \text { oral } \\
\text { contraceptive }(n=36)\end{array}$ & Overall $(N=36)$ \\
\hline Any adverse event & $6(16.7)$ & $5(13.9)$ & $6(16.7)$ & $17(47.2)$ \\
Alanine aminotransferase increased & 0 & $1(2.8)$ & $2(5.6)$ & $3(8.3)$ \\
Headache & $1(2.8)$ & $1(2.8)$ & $1(2.8)$ & $3(8.3)$ \\
Upper respiratory tract infection & $2(5.6)$ & 0 & $1(2.8)$ & $3(8.3)$ \\
Cough & $1(2.8)$ & 0 & $1(2.8)$ & $2(5.6)$ \\
\hline
\end{tabular}

Data are participants $[n(\%)]$

${ }^{a}$ Events occurring in $>1$ participant

UGT metabolism to the minor unstable metabolite M10 may have increased.

When vixotrigine was administered alone, $\mathrm{AUC}_{8}$ and $C_{\max }$ for the agent and its metabolites M14, M16, and M13 in this study were consistent with or slightly greater than earlier findings for the dose of vixotrigine $150 \mathrm{mg}$ three times daily at steady state in healthy adult and elderly men and women including healthy Japanese individuals [14, 15, 21]. The AUC and $C_{\max }$ values of ethinyl estradiol and levonorgestrel found in this study were also in line with their known pharmacokinetics, although earlier studies suggest both compounds display moderate variability in pharmacokinetics [36]. These similarities of all analytes with earlier studies lend validity to the exposure values reported in the current study.
The lack of effect on vixotrigine exposure is in contrast to findings from a study in which coadministration of vixotrigine with another UGT inducer (carbamazepine) reduced vixotrigine AUC within a dosing interval and $C_{\max }$ by $31.6 \%$ and $26.3 \%$, respectively [14]. However, as in the current study, the decreased exposure also was not considered clinically relevant, as it fell within pharmacokinetic variability. Vixotrigine metabolites M13 and M14 were also reduced on coadministration with carbamazepine. The greater effect of carbamazepine on vixotrigine concentrations compared with the oral contraceptive may be due to carbamazepine and ethinyl estradiol having different induction capacity towards different UGT isoforms.

Coadministration of vixotrigine and the oral contraceptive was well tolerated. The safety profile of vixotrigine was consistent with previous reports and no new safety trends were 
observed $[13,14,20]$. The frequency of AEs was similar across the three treatment periods and the most common AEs (occurring in one or more participants) were upper respiratory tract infection $(n=3)$, headache $(n=3)$, increased alanine aminotransferase $(n=3)$, and cough $(n=2)$. There was one serious $\mathrm{AE}$ of cholecystitis that was considered related to vixotrigine and the oral contraceptive. All other AEs were considered mild in severity.

Although TN occurs mostly in older adults (mean age, 51.5 years), it is reported in a notable proportion of women of childbearing age [26]. In addition, chronic neuropathic pain occurs more frequently in women than men [37]; hence, understanding the effects of oral contraceptives on the exposure of vixotrigine is important in this population.

\section{Conclusions}

Coadministration of vixotrigine and the oral contraceptive containing ethinyl estradiol and levonorgestrel had no clinically relevant effects on the exposure or safety of vixotrigine or the oral contraceptive's components. Findings of this study support the continued investigation of vixotrigine for the treatment of TN and other neuropathic pain conditions, and indicate that women of childbearing potential can be included in clinical trials without having to change their methods of contraception.

Acknowledgements Biogen sponsored this study and provided funding for medical writing support in the development of this paper; Meryl Mandle from Excel Scientific Communications wrote the first draft of the manuscript based on input from authors, and Adrienne Trout from Excel Scientific Solutions copy edited and styled the manuscript as per journal requirements. Biogen reviewed and provided feedback on the paper to the authors. The authors had full editorial control of the paper and provided their final approval of all content.

Author Contributions All authors contributed to the conception and planning of the work that led to the manuscript, or acquisition, analysis, and interpretation of the data, or both. All authors critically reviewed and provided input on the manuscript.

Data Availability The data that support the findings of this study are available from the corresponding author upon reasonable request, and are detailed at the following website: https://clinicalresearch.biogen.com.

\section{Compliance with Ethical Standards}

Funding This study was funded by Biogen.

Conflict of interest Yuan Zhao, Beth Tidemann-Miller, Romy Christmann, and Himanshu Naik are employees of and own stock/stock options in Biogen. Mark Versavel was a consultant for Biogen during this study.
Ethics Approval The trial was registered with ClinicalTrials.gov (NCT03324685) and conducted in accordance with the Declaration of Helsinki principles and Good Clinical Practice guidelines. The institutional review board of the clinic site (Covance Clinical Research Unit, Inc., Daytona Beach, FL, USA) provided approval of the protocol.

Consent to Participate All participants provided informed written consent.

Open Access This article is licensed under a Creative Commons Attribution-NonCommercial 4.0 International License, which permits any non-commercial use, sharing, adaptation, distribution and reproduction in any medium or format, as long as you give appropriate credit to the original author(s) and the source, provide a link to the Creative Commons licence, and indicate if changes were made. The images or other third party material in this article are included in the article's Creative Commons licence, unless indicated otherwise in a credit line to the material. If material is not included in the article's Creative Commons licence and your intended use is not permitted by statutory regulation or exceeds the permitted use, you will need to obtain permission directly from the copyright holder. To view a copy of this licence, visit http://creativecommons.org/licenses/by-nc/4.0/.

\section{References}

1. Merskey H, Bogduk N, editors. Classification of chronic pain: descriptions of chronic pain syndromes and definitions of pain terms. 2nd ed. Seattle: IASP Press; 1994.

2. van Hecke O, Austin SK, Khan RA, Smith BH, Torrance N. Neuropathic pain in the general population: a systematic review of epidemiological studies. Pain. 2014;155:654-62.

3. De Toledo IP, Conti Réus J, Fernandes M, et al. Prevalence of trigeminal neuralgia: a systematic review. J Am Dent Assoc. 2016;147:570-6.e2.

4. Maarbjerg S, Gozalov A, Olesen J, Bendtsen L. Trigeminal neuralgia - a prospective systematic study of clinical characteristics in 158 patients. Headache. 2014;54:1574-82.

5. Cruccu G. Trigeminal neuralgia. Continuum (Minneap Minn). 2017;23:396-420.

6. Cruccu G, Gronseth G, Alksne J, American Academy of Neurology Society; European Federation of Neurological Society, et al. AAN-EFNS guidelines on trigeminal neuralgia management. Eur J Neurol. 2008; 15:1013-28.

7. Zakrzewska JM, Linskey ME. Trigeminal neuralgia. BMJ Clin Evid. 2014;2014:1207.

8. Wiffen PJ, Derry S, Moore RA, Kalso EA. Carbamazepine for chronic neuropathic pain and fibromyalgia in adults. Cochrane Database Syst Rev. 2014;(4):CD005451.

9. Wieshmann UC, Baker G. Efficacy and tolerability of anti-epileptic drugs-an internet study. Acta Neurol Scand. 2017;135:533-9.

10. Meador KJ, Gevins A, Loring DW, et al. Neuropsychological and neurophysiologic effects of carbamazepine and levetiracetam. Neurology. 2007;69:2076-84.

11. Di Stefano G, La Cesa S, Truini A, Cruccu G. Natural history and outcome of 200 outpatients with classical trigeminal neuralgia treated with carbamazepine or oxcarbazepine in a tertiary centre for neuropathic pain. J Headache Pain. 2014;15:34.

12. Besi E, Boniface DR, Cregg R, Zakrzewska JM. Comparison of tolerability and adverse symptoms in oxcarbazepine and carbamazepine in the treatment of trigeminal neuralgia and neuralgiform headaches using the Liverpool Adverse Events Profile (AEP). J Headache Pain. 2015; 16:563. 
13. Zakrzewska JM, Palmer J, Morisset V, for the Study Investigators, et al. Safety and efficacy of a Nav1.7 selective sodium channel blocker in patients with trigeminal neuralgia: a double-blind, placebo-controlled, randomised withdrawal phase $2 \mathrm{a}$ trial. Lancet Neurol. 2017;16:291-300.

14. Dunbar J, Versavel M, Zhao Y, et al. Evaluation of the pharmacokinetic interaction between the voltage- and use-dependent Nav1.7 channel blocker vixotrigine and carbamazepine in healthy volunteers. Clin Pharmacol Drug Dev. 2020;9:62-73.

15. Naik H, Dunbar J, Layton G, Palmer J, Versavel M. Evaluation of the pharmacokinetics and tolerability of BIIB074, a Nav1.7-selective sodium channel blocker in adult and elderly male and female volunteers [poster PI-123]. Presented at the American Society for Clinical Pharmacology and Therapeutics (ASCPT) 119th Annual Meeting; 21-24 March, 2018; Orlando (FL).

16. Woodward C, Naik H, Versavel M, et al. Phase 1 study to evaluate the absorption, metabolism and excretion of the NAV1.7-selective sodium channel blocker BIIB074 [poster 162]. Presented at the International Society for the Study of Xenobiotics (ISSX) 21st North American Meeting; 24-28 September, 2017; Providence (RI).

17. Naik H, Steiner D, Versavel M, Palmer J, Fong R. Safety, tolerability, and pharmacokinetics of repeat doses of the Nav1.7-selective sodium channel blocker vixotrigine in healthy subjects [poster PII-003]. Presented at the American Society for Clinical Pharmacology and Therapeutics (ASCPT) 119th Annual Meeting; 21-24 March, 2018; Orlando (FL).

18. Naik H, Steiner D, Versavel M, Palmer J, Fong R. Safety, tolerability, and pharmacokinetics of single doses of the Nav1.7-selective sodium channel blocker BIIB074 in healthy subjects [poster PII004]. Presented at the American Society for Clinical Pharmacology and Therapeutics (ASCPT) 119th Annual Meeting; 21-24 March, 2018; Orlando (FL).

19. Naik H, Versavel M, Zhao Y, Miao X, Dunbar J. Effect of itraconazole on the pharmacokinetics of the Nav1.7-specific sodium channel blocker BIIB074 in healthy subjects [poster P081]. Presented at the American College of Clinical Pharmacology (ACCP) Annual Meeting; 17-19 September, 2017; San Diego (CA).

20. Fong R, Ballow CH, Naik H, Steiner D, Palmer J, White WB. Effects of a state- and use-dependent Nav1.7 channel blocker on ambulatory blood pressure: a randomized, controlled crossover study. J Clin Pharmacol. 2019;59:90-7.

21. Naik H, Versavel M, Dunbar J. Single and multiple dose pharmacokinetics (PK) and safety of vixotrigine in healthy Japanese and caucasian volunteers [poster PII-079]. Presented at the American Society for Clinical Pharmacology and Therapeutics (ASCPT) 120th Annual Meeting; 13-16 March, 2019; Washington, DC.

22. Daniels K, Abma JC. Current contraceptive status among women aged 15-49: United States, 2015-2017. NCHS data brief no. 327.
2018. https://www.cdc.gov/nchs/data/databriefs/db327-h.pdf. Accessed 24 Sept 2019.

23. Bezemer ID, Verhamme KM, Gini R, et al. Use of oral contraceptives in three European countries: a population-based multi-database study. Eur J Contracept Reprod Health Care. 2016;21:81-7.

24. Skouby SO. Contraceptive use and behavior in the 21 st century: a comprehensive study across five European countries. Eur J Contracept Reprod Health Care. 2010;15(Suppl. 2):S42-53.

25. ACOG Practice Bulletin No. 110: Noncontraceptive uses of hormonal contraceptives. Obstet Gynecol. 2010;115:206-18.

26. Koopman JS, Dieleman JP, Huygen FJ, de Mos M, Martin CG, Sturkenboom MC. Incidence of facial pain in the general population. Pain. 2009;147:122-7.

27. Hall GC, Carroll D, Parry D, McQuay HJ. Epidemiology and treatment of neuropathic pain: the UK primary care perspective. Pain. 2006;122:156-62.

28. Sabers A. Pharmacokinetic interactions between contraceptives and antiepileptic drugs. Seizure. 2008;17:141-4.

29. Zhang H, Cui D, Wang B, et al. Pharmacokinetic drug interactions involving 17alpha-ethinylestradiol: a new look at an old drug. Clin Pharmacokinet. 2007;46:133-57.

30. Nordette ${ }^{\circledR}-28$ (levonorgestrel and ethinyl estradiol tablets, $0.15 \mathrm{mg} / 0.03 \mathrm{mg}$ ) [product insert]. North Wales (PA): Teva Pharmaceuticals; 2017.

31. Alesse ${ }^{\circledR} 28$ tablets (levonorgestrel and ethinyl estradiol tablets) [product label]. Philadelphia (PA): Wyeth Pharmaceuticals Inc., a subsidiary of Pfizer Inc.; 2017.

32. US Department of Health and Human Services, Food and Drug Administration. Guidance for industry: statistical approaches to establishing bioequivalence. 2002. https://www.fda.gov/media/70958/ download. Accessed 14 Nov 2019.

33. Walle T, Fagan TC, Walle UK, Topmiller MJ. Stimulatory as well as inhibitory effects of ethinyloestradiol on the metabolic clearances of propranolol in young women. Br J Clin Pharmacol. 1996;41:305-9.

34. Reimers A, Helde G, Brodtkorb E. Ethinyl estradiol, not progestogens, reduces lamotrigine serum concentrations. Epilepsia. 2005;46:1414-7.

35. Sidhu J, Job S, Singh S, Philipson R. The pharmacokinetic and pharmacodynamic consequences of the co-administration of lamotrigine and a combined oral contraceptive in healthy female subjects. Br J Clin Pharmacol. 2006;61:191-9.

36. Jusko WJ. Perspectives on variability in pharmacokinetics of an oral contraceptive product. Contraception. 2017;95:5-9.

37. Colloca L, Ludman T, Bouhassira D, et al. Neuropathic pain. Nat Rev Dis Primers. 2017;3:17002. 